\title{
Short- and long-term follow-up results for cognitive interventions
}

\author{
ROBERT PASNAK and JANICE CAMPBELL \\ George Mason University, Fairfax, Virginia
}

\begin{abstract}
Follow-up results for two studies are presented. In both studies, learning-set instruction on early concrete operations-unidimensional classification, unidimensional seriation, and, in the second study, conservation-was offered to children who were not making normal progress. Improvements on psychometric tests of intelligence were associated with gains on the concrete operations. These improvements lasted for at least a year in the first study, and, in a reduced form, for 6 years in the second study.
\end{abstract}

Pasnak, Campbell, Perry, and McCormick (1989) and Pasnak et al. (1987) reported successful efforts to accelerate cognitive development. The first study involved 6- to 8-year-old children who were mildly mentally retarded. The second involved normal 5-year-olds who were having difficulty in kindergarten. The present paper is a report of follow-up results for those interventions.

Pasnak et al. (1989) worked with 6 children, 4 of them black, enrolled in a special education class (see Table 1 ). Five of these children (Child 2-Child 6) were taught unidimensional classification by a learning-set procedure. Each problem comprised four objects, one of which differed in one dimension. For 20 problems, the difference was form; for 20, it was size; for 20, it was orientation; for 20 , it was type or function; for 20 , it was texture. Texture problems involved a successive classification procedure, since the children were allowed to feel, but not see, the objects for these 20 problems.

All but Child 6 eventually solved all of classification learning-set problems. (Child 6 made no progress at all.) These 5 children and Child 1 , who could already classify, subsequently received learning-set instruction on seriation. Seriation problems required the children to align objects in order from the smallest to the largest. If there were more than three objects in the series, the child was required to seriate all but one of the subjects. The remaining object, usually a middle-sized one, then had to be inserted in its proper place within the series. (Inserting an item into an already-formed series is much more difficult than is constructing a series from scratch.)

The child who could classify without instruction solved 60 seriation problems, 15 consisting of three objects, 10 consisting of four, five, and six objects, and 5 consisting of seven, eight, and nine objects. Two of the children who had received classification instruction learned to solve the 15 problems that had three objects, but their instruction,

Correspondence should be addressed to Robert Pasnak, Department of Psychology, George Mason University, Fairfax, VA 22030.
Table 1

Age, Race, and Sex of Participating MMR Children

\begin{tabular}{cccl}
\hline Child & Age in Years & Race & Sex \\
\hline 1 & 6.67 & Black & Male \\
2 & 7.33 & Black & Male \\
3 & 7.67 & Black & Female \\
4 & 8.17 & Black & Female \\
5 & 6.83 & White & Male \\
6 & 8.00 & White & Male \\
\hline
\end{tabular}

and that of the other children, was terminated by the end of the school semester.

All children but the one who could not learn to solve any classification problems made gains on their classification posttests $[t(5)=2.45, p<.05]$. Only 2 children improved appreciably on their seriation posttests, but their improvement was sufficient to raise the mean of the group significantly $[t(5)=2.69, p<.05]$. The child gaining the most was the one who had mastered classification without instruction; he received the most seriation instruction.

The children also made significant gains on the Slosson Intelligence Test (SIT) $[t(5)=2.89, p<.05]$ and the Peabody Picture Vocabulary Test (PPVT) $[t(5)=6.06$, $p<.01]$. These tests were presented as generalization measures that might reflect increased cognitive competence.

The following year, no further instruction was offered on classification. However, the 4 children who had been able to profit from classification were given seriation instruction $15 \mathrm{~min}$ per week for $3 \frac{1 / 2}{2}$ months. Two of these children (Child 2 and Child 5 in Table 2) were ultimately able to master all of the seriation instruction problems. The other 2 children (Child 3 and Child 4) were unable to progress beyond problems that had three objects.

Table 1 presents scores for these children on their pretests and posttests. It also shows follow-up data that were collected 1 year after the initial posttest (6 weeks after the seriation instruction for Child 2-Child 5). No scores are given for Child 6, who had been unable to make any progress on classification or seriation and for whom no follow- 
Table 2

Pretest, Posttest, and Follow-up Test Scores

\begin{tabular}{lrrrrrr}
\hline & \multicolumn{6}{c}{ Child } \\
\cline { 2 - 7 } Test & 1 & 2 & 3 & 4 & 5 & $\bar{x}$ \\
\hline Classification & & & & & & \\
$\quad$ Pretest & 40 & 20 & 12 & 13 & 27 & 22.4 \\
Posttest & 42 & 42 & 24 & 19 & 33 & 32.0 \\
$\quad$ Follow-up & 44 & 35 & 35 & 19 & 37 & 34.0 \\
Seriation & & & & & & \\
$\quad$ Pretest & 4 & 8 & 2 & 3 & 5 & 4.4 \\
Posttest & 12 & 10 & 3 & 3 & 10 & 7.6 \\
Follow-up & 15 & 10 & 12 & 7 & 14 & 11.6 \\
Slosson IQ & & & & & & \\
$\quad$ Pretest & 59 & 43 & 48 & 49 & 60 & 51.8 \\
Posttest & 75 & 68 & 52 & 58 & 79 & 66.4 \\
Follow-up & 78 & 65 & 58 & 50 & 71 & 64.4 \\
PPVT Raw & & & & & & \\
Pretest & 36 & 36 & 5 & 39 & 20 & 27.2 \\
Posttest & 53 & 47 & 14 & 45 & 39 & 39.6 \\
Follow-up & 56 & & 23 & & 48 & \\
PPVT SSE & & & & & & \\
Pretest & 51 & 44 & $<40$ & $<40$ & $<40$ & \\
Posttest & 56 & 49 & $<40$ & $<40$ & $<46$ & \\
Follow-up & 61 & & $<40$ & & 43 & \\
\hline
\end{tabular}

Note-Child 1 received only seriation instruction. Child 3 could not respond meaningfully to the classification pretest, and so was awarded chance scores.

up data were collected. Also, Child 2 and Child 4 were not available for follow-up administration of the PPVT.

Analysis of variance shows a significant difference in the classification scores, even for this small sample $[F(2,8)=$ $7.04, p<.05]$. Pretest scores were significantly lower than the posttest and follow-up scores $[F(1,8)=13.71$, $p<.01]$. The posttest and follow-up scores do not differ $[F(1,8)=0.37, p>.05]$. Thus, without any further classification training, the gain from pretest to posttest has maintained itself for at least 1 year. The explanation may lie in the role of simple classification skills in ordinary thinking processes. At this age, increases in a child's classification abilities, from whatever source, are likely to be constantly strengthened and reinforced during daily interactions with home and school environments. Hence, it may be no surprise that the classification gains were maintained in the present case.

There also was an overall gain in seriation $[F(2,8)=$ $10.58, p<.01]$. In this case, pretest scores were significantly lower than posttest and follow-up scores $[F(1,8)=$ $14.66, p<.01$, and the follow-up scores were significantly higher than those on the initial posttest $[F(1,8)=$ $6.50, p<.05]$. This is not, of course, truly follow-up data, except in the case of Child 1 , because all of the other children received seriation instruction in the year after the initial posttest. The most obvious interpretation is that Child 1 at least held his gain, probably for the reason given in the preceding paragraph, and that the other children made new gains because of the new instruction.

The IQs as measured by the SIT showed the same pattern as the classification scores. There was a significant difference $[F(2,8)=10.18, p<.01]$, and it was be- tween the pretest scores and those made on the other two tests $[F(1,8)=20.20, p<.01]$. There was no difference between posttest and follow-up scores $[F(1,8)=0.33$, $p>$.05].

Thus, it appears that the overall gain in reasoning ability measured by the SIT persisted, as did the classification gains. On the other hand, it did not increase, even though the children were stronger in seriation.

The PPVT scores are problematic, since only 3 children took the follow-up test. It seems clear that the raw scores were not lower, and they should not have been since the children had an extra year to increase their vocabularies. The standard score equivalents available for 2 children appear to show no decline from the posttest, indicating that the children held their position relative to the national sample. This is a good showing for children who are mentally retarded. It may well reflect the continuing efforts of their teachers to build vocabularies as much as it does the increases in their classification and seriation abilities, if indeed there is a causal relationship.

In sum, this before-after design, with a 1-year followup, shows significant gains from pretest to posttest on four measures, and these gains lasted at least a year.

Pasnak et al. (1987), using a different research design, worked with children who were younger but more able. Two 5-year-old boys, who were having difficulty in kindergarten because of general cognitive delays, participated in their experiment. These boys had average or better pretest IQs on the Stanford Binet (SB) and the Wechsler Preschool and Primary Scale of Intelligence (WPPSI) and no known handicapping condition. Pretests showed that they were unable to classify successively, or to classify by type or function, whether objects were presented for examination or were simply named. They also lacked some seriation abilities and were unable to conserve number or substance. One boy (Boy A) was subsequently taught classification, seriation, substance conservation, and number conservation via a learning-set procedure in a multiple baseline design. The learning-set method was used to teach seriation, classification, and number conservation to Boy B, also in a multiple baseline design. This boy generalized perfectly from number conservation to substance conservation, so substance conservation instruction proved unnecessary.

Classification, seriation, and conservation tests were administered after the instruction (which took about $31 \frac{1}{2}$ months) was completed, and the SB and Wechsler Intelligence Scale for Children-Revised (WISC-R) were administered as generalization measures. (The boys were now too old for the WPPSI.) The IQ tests were readministered in a 1-year follow-up.

The pretest-posttest comparison showed that the boys made significant gains on classification, seriation, and both forms of conservation. Both also made large, significant gains on the Wechsler scales-performance, verbal, and full scale-and Boy B made a significant gain on the SB. The 1-year follow-up results for these tests showed that the gains on the verbal Wechsler scale dis- 
appeared, but those on the performance-scale scores and, consequently, the full-scale scores were substantially maintained. Boy B also maintained his gain on the SB.

The same two IQ tests were readministered for the present follow-up study. This administration took place 5 years after the initial 1-year follow-up (i.e., when the boys were completing the sixth grade, as opposed to the first grade). Their results, and those of the pretests, posttests, and 1-year follow-up tests, are presented in Table 3 as raw scores.

The first thing that emerges from Table 3 is that the follow-up scores are, with the exception of Boy A's SB, higher than the pretest scores. The differences on the verbal Wechsler scale for both boys and on the performance scale for Boy A are significantly higher. Conversely, the decline in Boy A's SB score is also statistically significant. His pretest performance on this test was problematic. The measured IQ was high, much higher than on the WPPSI, but obtained in an erratic way. At $5 \frac{1}{2}$ years of age, it was difficult to obtain ceilings, since he had widely scattered successes, some at up to twice his basal age, intermixed with many failures. The gradual decline in his SB score may be an instance of regularization with increasing maturity. Apart from this, it seems fair to conclude that the boys retained part of their gains on the IQ measures, whatever the source of those gains may be.

Differences between the pretest scores and scores on all posttests are shown in Table 4 in standard score form. This table shows that, while full-scale Wechsler scores were significantly higher than pretest scores in all but one comparison, the gains on the verbal and performance scales fluctuated unpredictably. Also, Boy B lost the gain he had made on the SB.

There are some significant declines when the 6-year follow-up scores are compared with those of the posttest immediately after the instruction. Boy A's SB declined significantly over the 6-year period, presumably for the reason hypothesized. His WISC-R scores tended to rise, although the changes were not statistically significant. This is the only positive note. Boy B's WISC-R scores were significantly lower, whether performance-scale $(z=3.43$,

Table 3 Stanford Binet and Wechsler IQ Scores

\begin{tabular}{|c|c|c|c|c|}
\hline & Pretest & Posttest & 1 Year & 6 Years \\
\hline \multicolumn{5}{|c|}{ Boy A } \\
\hline $\begin{array}{l}\text { Stanford Binet } \\
\text { WPPSI (WISC-R) }\end{array}$ & 128 & 125 & 122 & 113 \\
\hline Full & 106 & 119 & 117 & 123 \\
\hline Verbal & 116 & 124 & 120 & 123 \\
\hline Performance & 95 & 111 & 108 & 117 \\
\hline \multicolumn{5}{|c|}{ Boy B } \\
\hline $\begin{array}{l}\text { Stanford Binet } \\
\text { WPPSI (WISC-R) }\end{array}$ & 100 & 109 & 112 & 103 \\
\hline Full & 104 & 120 & 110 & 109 \\
\hline Verbal & 111 & 127 & 111 & 118 \\
\hline Performance & 95 & 108 & 108 & 96 \\
\hline
\end{tabular}

Table 4

Differences Between IQ Scores Expressed as Standard (z) Scores

\begin{tabular}{lcccc}
\hline & \multicolumn{4}{c}{ Pretest } \\
\cline { 2 - 5 } & $\begin{array}{c}\text { Stanford } \\
\text { Binet }\end{array}$ & Full & Verbal & Performance \\
\hline Posttest & & & & \\
$\quad$ Boy A & $-.51^{*}$ & 4.85 & 2.35 & 4.58 \\
$\quad$ Boy B & 2.00 & 5.97 & 4.71 & 3.72 \\
1-Year Follow-up & & & & \\
$\quad$ Boy A & -1.13 & 3.61 & 1.07 & 3.16 \\
Boy B & 2.79 & 1.97 & 0.00 & 3.16 \\
6-Year Follow-up & & & & \\
$\quad$ Boy A & -3.33 & 6.58 & 2.06 & 6.30 \\
Boy B & .67 & 1.87 & 2.06 & .29 \\
\hline
\end{tabular}

Note-The WISC-R replaced the WPPSI for follow-up tests. *Differences between pretest scores and posttest or follow-up scores are significant $(p<.05)$ when $z$ exceeds 1.96 .

$p<.05)$, verbal-scale $(z=2.64, p<.05)$, or full-scale $(z=4.10, p<.05)$ scores are considered.

There was also a (nonsignificant) decline in his SB. Thus, even though the 6-year follow-up scores were generally higher than those made before the intervention, they tended to be lower than those made immediately after it.

Results are mixed when the follow-up scores are compared for 1 and 6 years. Boy A's full-scale WISC-R was significantly higher at the 6-year follow-up than at the 1 -year follow-up $(z=2.01, p<.05)$, as was the performance scale $(z=2.26, p<.05)$. Boy $\mathrm{B}$, on the other hand, showed a significant decline on the performance scale $(z=3.00, p<.05)$.

This is mostly offset by a compensation rise on the verbal scale, so that the full-scale IQ is unchanged. On the other hand, both boys show a 9-point, statistically significant $(z=2.00, p<.05)$ decline on the SB from the 1-year follow-up to the 6-year follow-up. The fairest interpretation of the results is that verbal- and full-scale WISC-R scores may have stabilized while performance scores remained labile; SB scores declined.

In sum, this long-term follow-up seems to show that some of the effects of the initial intervention are still present and that, for one boy, but not the other, some of the immediate gains have been lost. Of course, not much confidence can be placed in the generality of these observations, since they are based on only 2 children. The variability of the results for even these 2 children suggests even greater caution in attempting to predict the results that might be obtained for other children.

Both studies are consistent in showing that IQ gains immediately after the intervention did not disappear in the following year. This is consistent with the idea that improvement in the concrete operations of unidimensional classification, unidimensional seriation, and perhaps early forms of conservation are associated with lasting changes in more general thinking abilities. This is an attractive possibility when children who are chronologically mature are the beneficiaries of instruction on early concrete operations. The children needed competence in these basic operations to compete with age peers in and out of school. 
Any advances in such thinking abilities would probably be reinforced by the natural, social, and academic environments. Since they are highly correlated with scores on psychometric IQ tests, it may not be surprising that changes in concrete operations were accompanied by changes in IQ measures. These children were at an age where changes in IQ scores, especially upward changes, can be expected (McCall, Applebaum, \& Hogarty, 1973).

The possibility of a very gradual drift back towards preintervention levels of functioning cannot be discounted. The early concrete operations so essential to a young child's cognitive functioning are not sufficient for an older child. More advanced thinking abilities are needed as the child matures. The children in these studies might be expected to acquire new cognitive operations at the same slow rates as had put them behind in the first place. Hence, a gradual return to their original relative position vis-àvis their age peers on psychometric measures at general reasoning ability might well be expected.

A more important problem is that the IQ measures used in these two studies are generalization measures. Neither study provides direct evidence that the IQ changes are the result of the increased competence in cognitive operations. In fact, the before-after design at the field research by Pasnak et al. (1989) does not even prove that the improvement in concrete operations was the result of the interven- tion. It seems unlikely that it was not, since children with this degree of retardation usually do not classify or seriate well until every early adolescence (McCormick, Campbell, Perry, \& Pasnak, 1990), and the multiple baseline design employed by Pasnak et al. (1987) does provide an acceptable basis for attributing concrete operational gains to the learning-set instruction. Even in the latter study, however, the conclusion that the associated IQ changes were caused by the intervention can only be regarded as a hypothesis that has not yet been proven or disproven.

\section{REFERENCES}

McCall, R., Applebaum, M., \& Hogarty, P. (1973). Developmental changes in mental performance. Monographs of the Society for Research in Child Development, 38(3, Serial No. 150).

McCormick, P., Campbell, J., Perry, P., \& Pasnak, R. (1990). Instruction of 8- to 13-year-olds mentally retarded children on Piagetian concepts. Mental Retardation, 28, 359-366.

Pasnak, R., Brown, K., Kurkian, M., Mattran, K., Triana, E., \& Yамамото, N. (1987). Cognitive gains through training on classification, seriation, and conservation. Genetic, Social, \& General Psychology Monographs, 113, 295-321.

Pasnak, R., Campbell, J., Perry, P., \& McCormick, P. (1989). Piacceleration instruction for children who are mentally retarded. Education \& Training in Mental Retardation, 24, 352-362.

(Manuscript received December 28, 1990.) 